\title{
Temperature monitoring using polymer optical fiber with integration to the internet of things
}

\author{
Hazura Haroon, Siti Khadijah Idris, Anis Suhaila Mohd Zain, \\ Hanim Abdul Razak, Fauziyah Salehuddin \\ Center for Telecommunication Research and Innovation, Faculty of Electronic and Computer Engineering, \\ Universiti Teknikal Malaysia Melaka, Hang Tuah Jaya, 76100 Durian Tunggal, Melaka, Malaysia
}

\section{Article Info \\ Article history: \\ Received Dec 23, 2019 \\ Revised Mar 12, 2020 \\ Accepted May 24, 2020 \\ Keywords: \\ Fiber optic \\ Internet of Things \\ Polymer optical fiber \\ Temperature sensor}

\begin{abstract}
In this paper, a polymer optical fiber (POF) is applied for temperature measuring of water solution using a light source of $650 \mathrm{~nm}$. The aim is to analyse the impact of temperature variations on the output of POF sensor device in terms of output power and sensitivity. From the study, the POF sensor shows a linear trend when the temperature is increased from $30^{\circ} \mathrm{C}$ to $80^{\circ} \mathrm{C}$ with the sensitivity of the polymer optical fiber for output power to the temperature are $0.00973 \mathrm{dBm} /{ }^{\circ} \mathrm{C}$ or $0.14797 \mathrm{nW} /{ }^{\circ} \mathrm{C}$, for optical characterization and $0.0011 \mathrm{~V} /{ }^{\circ} \mathrm{C}$ for electrical characterization. The integration of the Internet of Things to the system helps the user to monitor the temperature of various spaces anywhere at any time. The sensed values are controlled by Arduino Uno R3 and then sent to Blynk to provide wireless monitoring by the user.
\end{abstract}

This is an open access article under the CC BY-SA license.

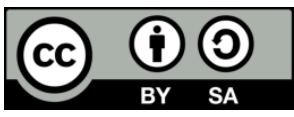

\section{Corresponding Author:}

Hazura Haroon,

Center for Telecommunication Research and Innovation,

Faculty of Electronic and Computer Engineering,

Universiti Teknikal Malaysia Melaka,

Hang Tuah Jaya, 76100 Durian Tunggal, Melaka, Malaysia.

Email: hazura@utem.edu.my

\section{INTRODUCTION}

The most commonly evaluated physical parameter in the process industry or in controlled environments is temperature. Therefore, accurate measurements are crucial to achieve stability. In many applications such as medical applications, laboratory materials research, electronic or electrical component studies, biological research, and geological surveys, precise measurements are necessary. Temperature sensor offers great benefits to the user to observe and control the real-time temperature of the surrounding [1-4]. Up to this time, sensors used to evaluate temperatures such as thermostats, thermocouples, thermometers and temperature resistance detectors are based on electronic methods [5]. These sensors are broadly employed in many fields including the industry, medical, modern agriculture, food and beverage, and home appliances [6-8]. Recently, optical sensor systems are seen as an alternative to these conventional, less flexible, and rigid electronic devices.

Fiber optic sensor is an innovation, which enables light changes guided by fiber optics to be observed when subjected to external physical, organic, chemical, or other parameters. The benefit of a fiberoptic-based sensor is a massive bandwidth capable of transmitting higher data than a conventional copper wire. Besides, it opposes the electromagnetic interference (EMI) and radio frequency interference (RFI) of wireless communication [9]. The sensor can even be placed in the remote area, competent to measure parameter at an inaccessible location and do not has an electrical charge that fits in a hazardous area [10, 11]. Furthermore, the sensor is easy to install for expansion and can deal with the application of a wide variation 
of temperature [12-15]. Therefore, due to vast advantages, polymer optical fiber (POF) is applied in this project for temperature measuring using a light source of $650 \mathrm{~nm}$. Several advantages of POF are that it has massive flexibility, easier handling, long length, compact size and lightweight, inaccessible installation, resistance to extreme environments and no interference with electromagnetic fields [16-18]. The integration to the internet of things (IoT) system at the receiver part helps the user to monitor the temperature of various space anywhere at any time. The detected sensor is controlled by Arduino Uno R3 microcontroller and then sent to the Blynk application to provide wireless monitoring for user notification. To the best of our knowledge, integrating the fiber optic sensor to the IoT platform is still new, and the feasibility of IoT technology is expected to boost the growth of fiber optic sensor.

\section{EXPERIMENTAL}

The temperature measurement is carried out in two stages, the optical characterization and the electrical characterization. Figure 1 shows the experimental setup for temperature measurement of optical characterization. For the setup, the input power of the red LED of wavelength $650 \mathrm{~nm}$ is connected to a POF sensor, while the other end is connected to optical power meter for detection. The aim for optical characterization is to observe the dependence of optical output power to the temperature variation. The sensor sensing area is fabricated by the etching process and dipped into a measuring liquid, where the beaker is placed on the hotplate. The length of the POF is about $1 \mathrm{~m}$, with sensing area at the middle of the fiber is about $2 \mathrm{~cm}$. Deionized (DI) water in the beaker is heated by using a hotplate to increase the temperature of the solution, while the output power is observed from the optical power meter. Origin Pro 8 software is used to plot the output results in a graph. The readings for DI water solution temperatures are repeated five times and average reading is taken as the final result. The sensor probe is cleaned with acetone liquid and dried before another liquid testing is done.

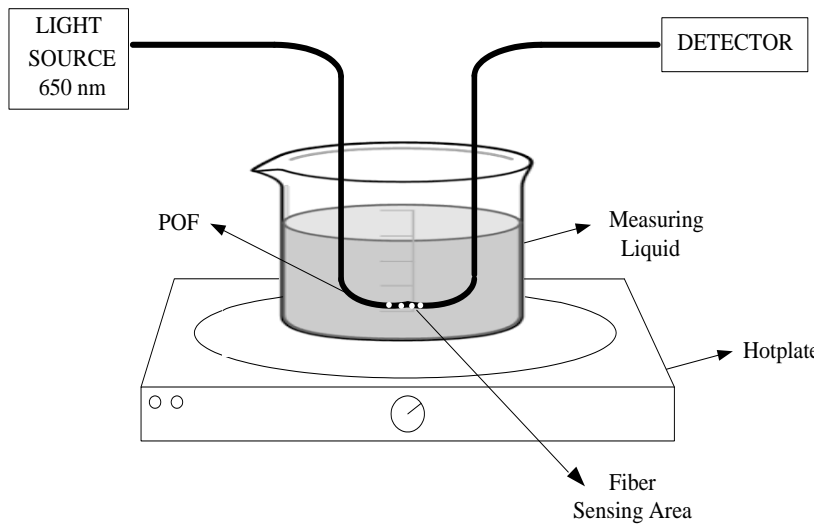

Figure 1. Experiment set-up for optical characterization

For electrical characterization, the setup is as shown in Figure 2. The receiver circuit which consists of the main component of photodiode IF-D91 and a dual-rail to rail operational amplifier LM358P are used to amplify and convert the optical to an electrical signal. A dual-rail to rail operational amplifier (Op-amp), LM358P is chosen for the receiver circuit design due to high input impedance and a wide range of supply voltage that is provided in microcontroller Arduino Uno R3. Op-amp needed $+5 \mathrm{~V}$ and $-5 \mathrm{~V}$ supply voltages to operate. The inverting input of LM358P attaches to the photodiode and the non-inverting attaches to ground. The output rom the receiver will be in voltage value. The multimeter is employed for measuring the voltage as the temperature changes.

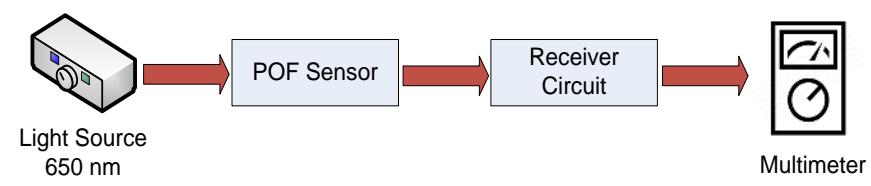

Figure 2. Experiment set-up for electrical characterization 


\section{RESULTS AND ANALYSIS}

\subsection{Fabrication of POF sensor}

In order to design the fiber optic sensor, the sensor's probe has to be fabricated to make it possible to sense the presence of a solution surrounding the core surface [19]. In this project, the change in temperature of the water solution leads to a change in output power measurement. Hence, exposing the core of fiber optic is necessary so that it is in contact with the surroundings by removing the jacket and cladding of fiber optic. Polymer optical fiber cable with 1 meter length was used for the preparation of the fiber optic sensor. As many $2 \mathrm{~cm}$ of fiber jacket was removed at the center of the cable by using a fiber cutter [20]. After the fiber jacket was removed, the etching process was done to remove the cladding on the core of the fiber optic by dipping the exposed area with Acetone solution [21]. The exposed core will perform as a sensor probe. Finally, the cladding residue on the sensing area of POF was cleaned using an alcohol solution, which was Isopropyl. An image analyzer was used to measure the sample's diameter after etching is done with initial core and cladding diameter measurement was $1016.216 \mu \mathrm{m}$.

Figure 3 shows the measurement of the core diameter of polymer optical fiber sensor probe. After etching time of $2 \mathrm{~s}$, it was found that fiber core diameter was $982.422 \mu \mathrm{m}$. Since only a slight core exposure is needed, the diameter observed is adequate to ensure the core is slightly exposed, due to the initial diameter of the core is only around $1000 \mu \mathrm{m}$. Etching the fiber more than $2 \mathrm{~s}$ will cause the fiber to over etched [22]. For instance, shown in Figure 4, with 8 s etching time, the core diameter was reduced to 906.757 $\mu \mathrm{m}$. Further core thinning will tend to break the fiber, therefore $2 \mathrm{~s}$ was selected as the best etching time.

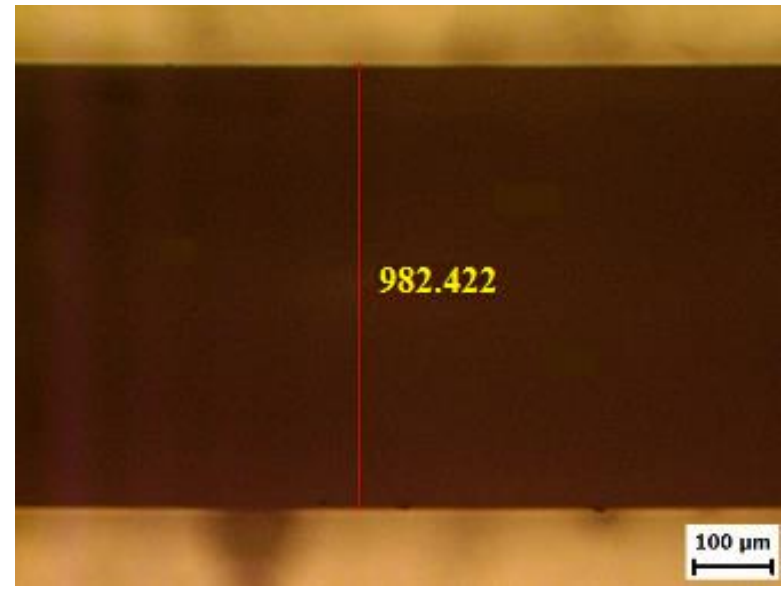

Figure 3. Etching side view measurement of fiber sensor probe for etching time $=2 \mathrm{~s}$

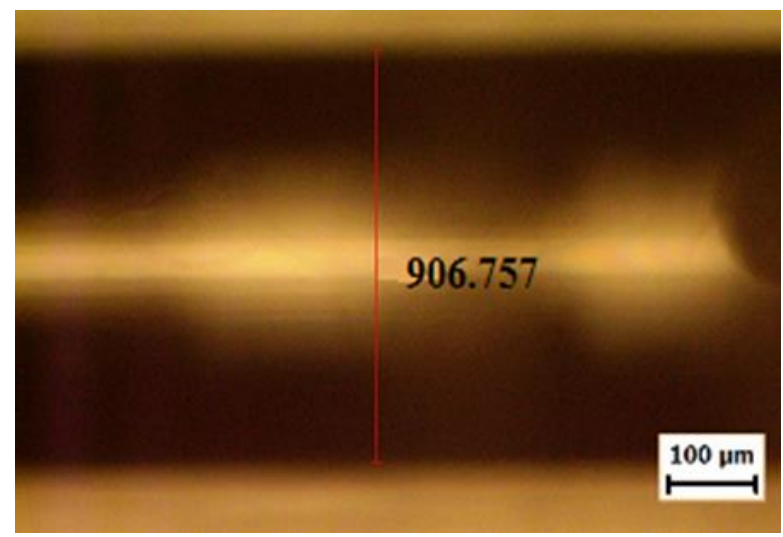

Figure 4. Etching side view measurement of fiber sensor probe for etching time $=8 \mathrm{~s}$

\subsection{Optical measurement of liquid temperature}

For the optical characterization of the temperature, the POF sensor was connected to a light source of a red light-emitting diode (LED) whilst another tip end was connected to the optical power meter (OPM)

Temperature monitoring using polymer optical fiber with integration to the internet...(Hazura Haroon) 
to measure the output power. In this experiment, the light source of a red LED of wavelength $650 \mathrm{~nm}$ was used. Figures 5-6 show the graph of optical power in $\mathrm{dBm}$ and nanoWatt $(\mathrm{nW})$ against the temperature. Five samples of data were collected for each temperature reading to get better accuracy. The graph in Figure 5 shows that the rise of the temperature has resulted in the rise of the output power in $\mathrm{dBm}$. Figure 6 also shows a linearly increasing graph. When the temperature was increased, the output power in $\mathrm{nW}$ increased too. The result can be related to the previous research by A. Tapetado [9], Luo [23], and Leal [24], showing similar trend, whereas the temperature of the surrounding medium is increased, the power variation also increased.

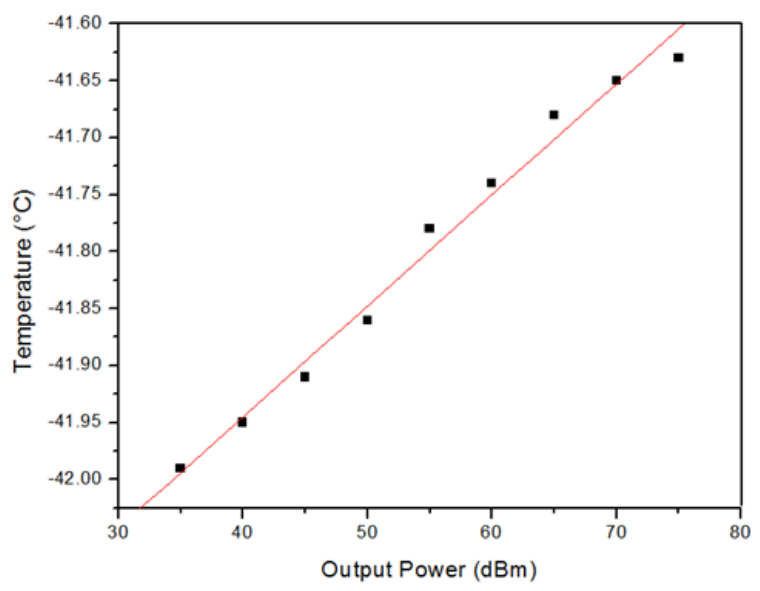

Figure 5. Output power $(\mathrm{dBm})$ versus temperature

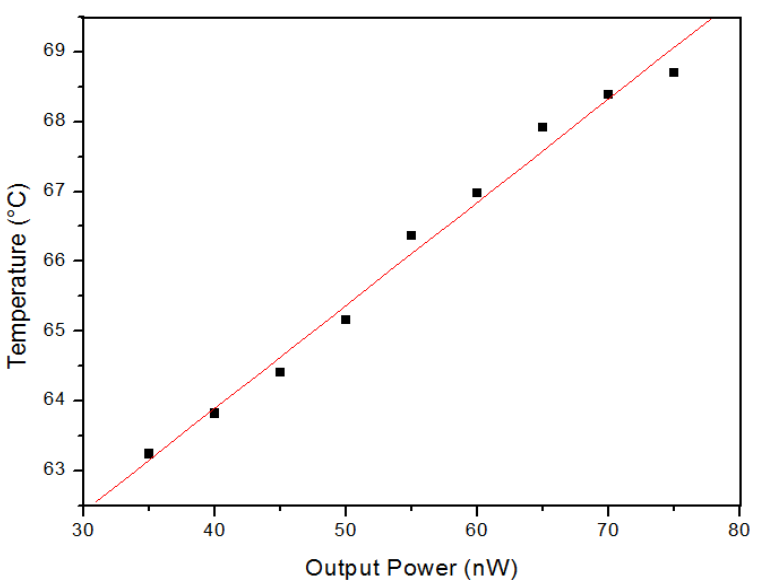

Figure 6. Output power $(\mathrm{dBm})$ versus temperature output power $(\mathrm{nW})$ versus temperature $\left({ }^{\circ} \mathrm{C}\right)$ graph

From both Figures 5 and 6, they show the mathematical model to estimate the sensor performance can be estimated. The linear fit best line of both figures has the general mathematical equation as:

$$
y=m T+c
$$

where: $y \quad=$ Output power

$T=$ Temperature of water

$C=$ y-intercept in line graph

The equation represents the $y$ as the output power, $T$ as the temperature of the water and $c$ as the y-intercept in the line graph. Table 1 shows mathematical modelling for optical measurement against the temperature of the water. From the mathematical modelling, the sensitivity of the polymer optical fiber sensor can be determined by the gradient of the graph, which is $0.00973 \mathrm{dBm} /{ }^{\circ} \mathrm{C}$ or $0.14797 \mathrm{nW} /{ }^{\circ} \mathrm{C}$.

Table 1. Mathematical modelling for optical measurement

\begin{tabular}{ll}
\hline \multicolumn{1}{c}{ Parameter } & \multicolumn{1}{c}{ Mathematical Modelling } \\
\hline Optical $(\mathrm{dBm})$ & $\mathrm{P}(\mathrm{dBm})=0.00973(T)-42.33422$ \\
Optical $(\mathrm{nW})$ & $\mathrm{P}(\mathrm{nW})=0.14797(T)+57.97183$ \\
\hline
\end{tabular}

\subsection{Electrical measurement for liquid temperature}

For electrical characterization, the input source of light of red LED with wavelength 650nm was supplied to the polymer optical as input whilst the tip end of POF was attached to a receiver circuit, which consists of a photodiode and an amplifier for output voltage measurement. A digital multimeter was used to measure the voltage. Table 2 shows the voltage measured in volts (V) for temperature from $30^{\circ} \mathrm{C}$ to $80^{\circ} \mathrm{C}$. Five samples of data are collected for each temperature reading. The table summarizes the average reading of the output voltage in volt $(\mathrm{V})$. Based on Table 2, the output voltage gradually increased when the temperature was increased. 
Table 2. Measurement of the output voltage at different temperature

\begin{tabular}{cc}
\hline Temperature $\left({ }^{\circ} \mathrm{C}\right)$ & Output voltage $(\mathrm{V})$ \\
\hline 30 & 0.566 \\
35 & 0.574 \\
40 & 0.578 \\
45 & 0.583 \\
50 & 0.589 \\
55 & 0.594 \\
60 & 0.596 \\
65 & 0.603 \\
70 & 0.610 \\
75 & 0.621 \\
80 & 0.632 \\
\hline
\end{tabular}

Figure 7 shows the graph of output voltage versus the water temperature. The line graph of the figure shows a linear result. The rise of the temperature of the water has resulted in the rise of the output voltage in Volts. The result can be verified by [25], which shows the similar trend for liquid temperature measurement. Table 3 shows the mathematical modelling for electrical measurement for water temperature monitoring. From the mathematical modelling, the sensitivity of the polymer optical fiber in terms of the output voltage to the temperature variations was $0.00110 \mathrm{~V} /{ }^{\circ} \mathrm{C}$.

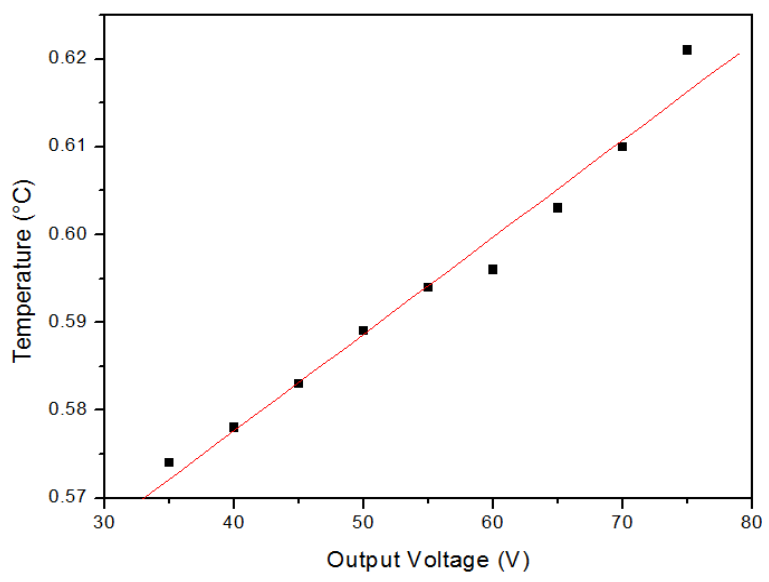

Figure 7. Output voltage $(\mathrm{V})$ versus temperature $\left({ }^{\circ} \mathrm{C}\right)$ graph

Table 3. Mathematical modelling for electrical measurement

\begin{tabular}{cc}
\hline Parameter & Mathematical modelling \\
\hline Electrical $(\mathrm{V})$ & $\mathrm{P}(\mathrm{v})=0.00110(T)+0.53354$ \\
\hline
\end{tabular}

\subsection{Integration with IoT}

The block diagram connecting the optical sensor to the IoT platform is illustrated as in Figure 8 .

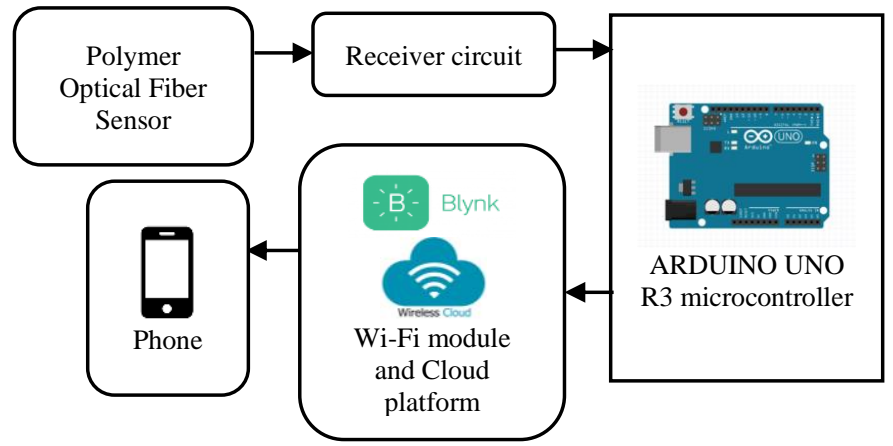

Figure 8. Graph Block diagram of IoT integration to POF sensor 
The voltage value from the receiver circuit is sent to the control unit, which consists of Arduino UNO R3 microcontroller and cloud platform. The printed circuit board (PCB) layout of the receiver circuit in Proteus 8 software design is shown in Figure 9, whilst the wireless network circuit is shown as in Figure 10. The project was supplied by using a red LED of $650 \mathrm{~nm}$ as the input power for the POF sensor. The LED was turned on using voltage supply $+5 \mathrm{~V}$ DC from microcontroller Arduino Uno R3. In this system, ESP8266 was used to connect the Arduino Uno R3 microcontroller with a wireless network.

A wireless network is needed to send all the data to the cloud platform. The cloud service chosen for this system is Blynk. All the values detected by the sensor were sent to Blynk through a wireless network. Blynk is also functioning as the mobile application for the user to monitor the output voltage of the electrical signal of the fiber optic sensor. The value detected by the sensor was read and the value will be displayed on the mobile phone. The reading of the POF sensor output voltage can be viewed through the Blynk Application to make it easier for the user to monitor wirelessly. Figure 11 shows an example of an output display on the Blynk application from a smartphone.

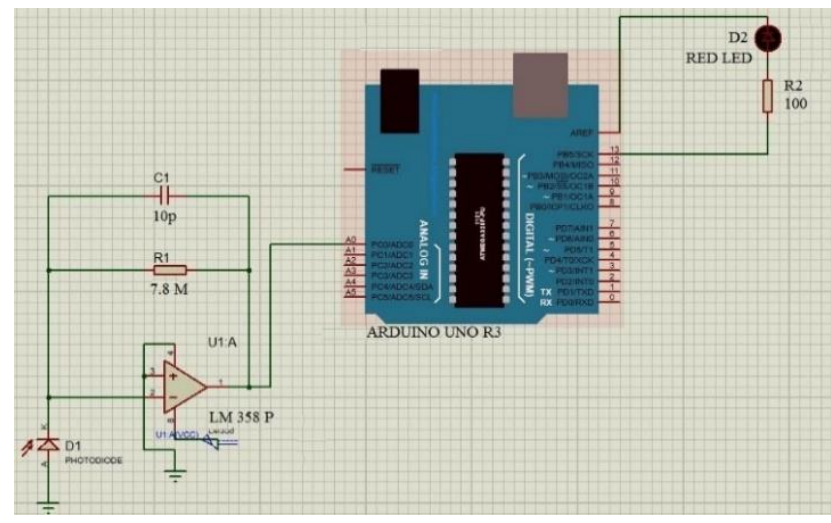

Figure 9. Schematic circuit of the receiver circuit

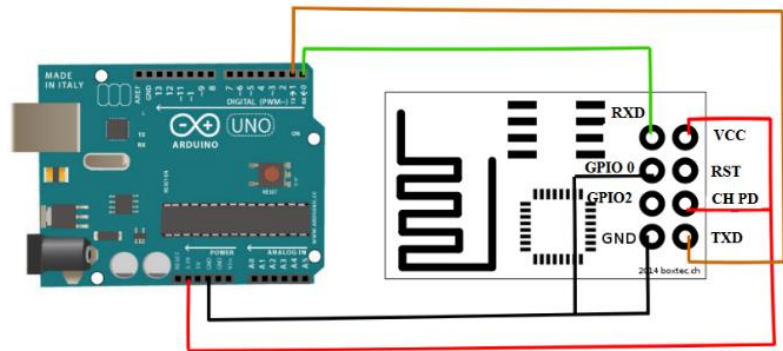

Figure 10. Wireless network circuit

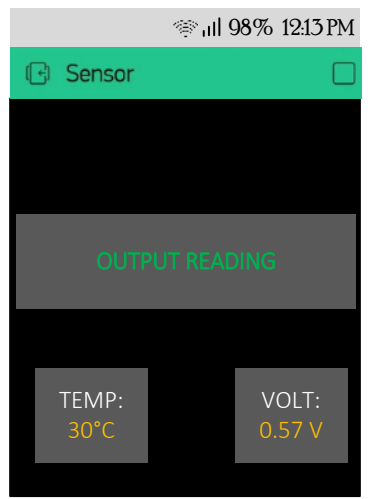

Figure 11. An example of the voltage display on the smartphone by the Blynk application 


\section{CONCLUSION}

A temperature sensor based on fibre-optic technology has been designed and tested. The research has been accomplished with an environmentally safe prototype by using POF has been developed. This fully functional temperature monitoring system with the integration to the IoT technology has been successfully tested for temperature measurement in the range of $30^{\circ} \mathrm{C}$ to $80^{\circ} \mathrm{C}$. The outputs show a linear respond of output power and voltage to the changes in temperature. It was concluded that as the temperature increased, the higher the output power and output voltage of the fibre optic sensor. The sensitivity of the polymer optical fiber determined in this study was $0.00973 \mathrm{dBm} /{ }^{\circ} \mathrm{C}$ or $0.14797 \mathrm{nW} /{ }^{\circ} \mathrm{C}$ for optical characterization and $0.00110 \mathrm{~V} /{ }^{\circ} \mathrm{C}$ for electrical characterization. Future works will be emphasized on a deeper analysis of IoT temperature monitoring mechanisms, including multiple sensors and environmental effects.

\section{ACKNOWLEDGEMENTS}

Our thanks to Universiti Teknikal Malaysia Melaka (UTeM) for the support.

\section{REFERENCES}

[1] M. Amanzadeh, S. M. Aminossadati, M. S. Kizil, and A. D. Raki, "Recent developments in fi bre optic shape sensing," Measurement, vol. 128, no. June, pp. 119-137, 2018.

[2] H. Haroon and A. Kareem, "Statistical analysis on impact of temperature to fiber Bragg grating sensor performance," Optoelectronics and Advanced Materials-Rapid Communications, vol. 13, no. 5-6, pp. $290-294,2019$.

[3] Y. H. P. Isnomo, M. N. Zakaria, M. Junus, M. A .Anshori, and A. Aisah, "Optical fiber temperature sensor design," IOP Conf. Series: Materials Science and Eng. The 1st Ann. Tech. Applied Sci., and Eng. Conf., vol. $732,2020$.

[4] S. K. Idris, H. Haroon, H. A. Razak, and A. S. M. Zain, "Investigation on fiber optic sensor using FBG for various temperature and liquid density," Journal of Physics: Conference Series, vol. 1502, no. 1, p. $012009,2020$.

[5] A. Tapetado, P. J. Pinzón, J. Zubia, and C. Vázquez, "Polymer optical fiber temperature sensor with dual-wavelength compensation of power fluctuations," Journal of Lightwave Technology, vol. 33, no. 13, pp. 2716-2723, July 2015.

[6] H. A. Razak, N. H. Sulaiman, H. Haroon, and A. S. M. Zain, "A fiber optic sensor based on Mach-Zehnder interferometer structure for food composition detection," Microwave and Optical Technology Letters, vol. 60, no. 4, pp. 920-925, 2018.

[7] M. de F. F. Domingues and A. Radwan, "Optical fiber sensors for loT and smart devices: Optical fiber sensors in IoT," Springer Publishing Company, pp. 73-86, 2017.

[8] C. R. U. Kumari, D. Samiappan, Kumar R., and T. Sudhakar, "Fiber optic sensors in ocean observation: A comprehensive review," Optik, vol. 179, pp. 351-360, 2019

[9] Y. Kwon, K. Naeem, M. Y. Jeon, and I-B. Kwon, "Enhanced sensitivity of distributed-temperature sensor with Al-coated fiber based on OFDR," Optical Fiber Technology, vol. 48, pp. 229-234, 2019.

[10] N. Jing, C. Teng, J. Zheng, G. Wang, M. Zhang, and Z. Wang, "Temperature dependence of light power propagation in bending plastic optical fiber," Optical Fiber Technology, vol. 31, pp. 20-22, 2016.

[11] P. J. Thomas and J. O. Hellevang, "A high response polyimide fiber optic sensor for distributed humidity measurements," Sensors and Actuators B: Chemical, vol. 270, pp. 417-423, 2018.

[12] H-E. Joe, H. Yun, S-H. Jo, M. B. G. Jun, and B-K. Min, "A review on optical fiber sensors for environmental monitoring," International Journal of Precision Engineering and Manufacturing-Green Technology, vol. 5, no. 1, pp. 173-191, 2018.

[13] G. Bashan, Y. London, H. H. Diamandi, and A. Zadok, "Distributed cladding mode fiber-optic sensor," Optica, vol. 7, no. 1, 2020, pp. 85-92, 2020.

[14] M. Kassim, A. S. Arif Mohd Zaid, A. Idris, S. Shahbudin, R. Mohamad, C. K. H. C. Ku Yahaya, "3D modeling of multimode and single mode fiber, "Indonesian Journal of Electrical Engineering and Computer Science, vol. 16, no. 3, pp. 1398-1406, 2019.

[15] W. Talataisong, R. Ismaeel, and G. Brambilla, "A review of microfiber-based temperature sensors review," Sensors (Basel), vol. 18, no. 2, pp. 461, 2018.

[16] H. Haroon, A. A. A. Mansor, H. A. Razak, S. K. Idris, A. S. M. Zain, and F. Salehuddin, "Experimental performance analysis of macrobending loss characteristics in polymer optical fiber," Journal of Advanced Research in Applied Sciences and Engineering Technology, vol. 14, no. 1, pp. 1-7, 2019.

[17] H. Haroon, S. K. Idris, M. Y. Yusoff, A. S. M. Zain, H. A. Razak, F. Salehuddin, and M. Z. N. Syaimaa, "Design and implementation of fiber optic sensor for soil moisture detection," Journal of Telecommunication, Electronic and Computer Engineering, vol. 10, no. 2-5, pp. 131-134, 2018.

[18] A. G. Leal-Junior, C. A. Diaz, L. M. Avellar, M. J. Pontes, C. Marques, and A. Frizera, "Polymer optical fiber sensors in healthcare applications: A comprehensive review," Sensors, vol. 19, no. 14, p. $3156,2019$.

[19] Y. Koike, T. Ishigure, and E. Nihei, "High-bandwidth graded-index polymer optical fiber," Journal of Lightwave Technology, vol. 13, no. 7, pp. 1475-1489, July 1995.

[20] J-R. Lee, D. Dhital, and D-J. Yoon, "Investigation of cladding and coating stripping methods for specialty optical fibers," Optic and Lasers in Engineering, vol. 49, no. 3, pp. 324-330, 2011. 
[21] A. R. A. Rashid, A. A. Nasution, A. H. Suranin, N. A. Taib, W. M. Mukhtar, K. A. Dasuki, and A. A. Ehsan, "Chemical tapering of polymer optical fiber," International Conference on Applied Photonics and Electronics, vol. 162, pp. 1-5, 2017.

[22] L. U. Jun and W. U. Zhengnan, "Research and design of internet of things information monitoring system based on fiber optic sensing," 2016 4th International Conference on Machinery, Materials and Computing Technology, pp. 1986-1990, 2016.

[23] D. Luo, Y. Yue, P. Li, J. Ma, L. Zhang, Z. Ibrahim, and Z. Ismail, "Concrete beam crack detection using tapered polymer optical fiber sensors," Measurement, vol. 88, pp. 96-103, 2016.

[24] A. Leal-Junior, A. Frizera, C. Marques, and M. J. Pontes "Polymer-optical-fiber-based sensor system for simultaneous measurement of angle and temperature," Applied Optics, vol. 57, no. 7, pp. 1717-1723, 2018.

[25] Md R. R. Khan and S-W. Kang, "Highly sensitive temperature sensors based on fiber-optic PWM and capacitance variation using thermochromic sensing membrane," Sensors (Basel), vol. 16, no. 7, p. 1064-2-14, 2016.

\section{BIOGRAPHIES OF AUTHORS}
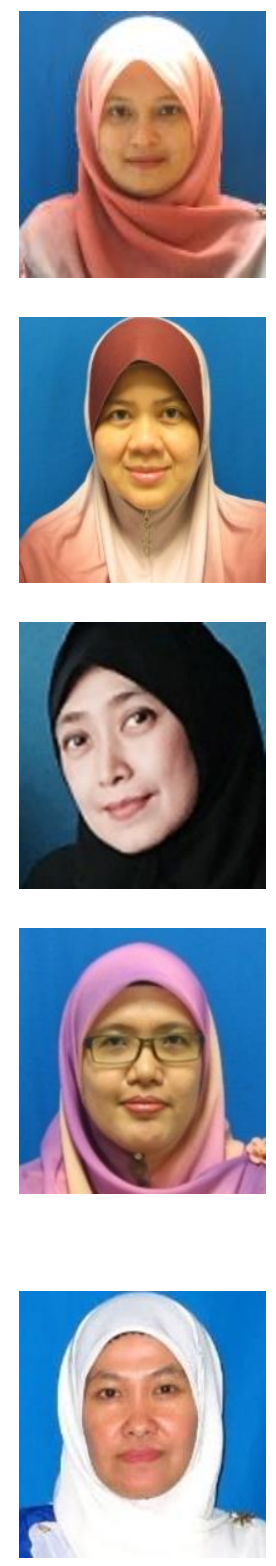

Hazura Haroon received B. Eng and M.Eng degrees in Electrical Engineering from Universiti Teknologi Malaysia (UTM), Malaysia in the year 2001 and 2004, respectively. Her doctoral degree is from Universiti Kebangsaan Malaysia (UKM), Malaysia. She has been in teaching profession since 2002. She is currently senior lecturer in Faculty of Electronics and Computer Engineering, Universiti Teknikal Malaysia Melaka (UTeM). Microengineering, Photonics and Optical Communications are the areas of her interest.

Siti Khadijah Idris @ Othman received her PhD. in Electrical and Electronic Engineering from University of Strathclyde, Glasgow Scotland in 2014 and MSc and BEEE (Hons.) from Universiti Kebangsaan Malaysia in the year 1999 and 2002 respectively. She is currently a Senior Lecturer in Faculty of Electronics and Computer Engineering, Universiti Teknikal Malaysia Melaka (UTeM). Her research interests include OCDMA, Optical Fiber communication and Optical Fiber sensor. She has contributed over 40 technical papers in various journals and conferences.

Anis Suhaila received Bachelor Engineering (Electric, Electronics \& System) and Master (Microelectronics) degrees from National University of Malaysia (UKM) in 2000 and 2001 respectively. In 2013, she got $\mathrm{PhD}$ degree in Electronics and Electrical Engineering from University of Glasgow, U.K. Her research interest includes nanoscale devices, variability and reliability, modelling and simulations, IC design for biomedical applications.

Hanim Abdul Razak received Bachelor of Computer and Information Engineering from International Islamic University Malaysia (IIUM) in 2003. Then, she joined KUTKM(now known as UTeM) as a tutor and pursued her MSc in Microelectronics in Universiti Kebangsaan Malaysia (UKM) in which she completed in 2006. After serving UTeM as a lecturer for several years, she was awarded a scholarship to further study in Doctor of Philosophy in Microengineering and Nanoelectronics at Universiti Kebangsaan Malaysia (UKM) and completed in 2014. She is currently a Senior Lecturer in Faculty of Electronics and Computer Engineering, Universiti Teknikal Malaysia Melaka (UTeM). Microengineering, Photonics and Microelectronics are the areas of her interest.

F. Salehuddin received the B.Sc. degree in electrical engineering (Communication) from Universiti Teknologi Mara (UiTM), Malaysia in 2001 and the M.Sc. degree in Electrical, Electronic and System Engineering from Universiti Kebangsaan Malaysia, in 2003. She received the Ph.D. degree in Microelectronics Engineering from Universiti Tenaga Nasional (UNITEN), Malaysia in 2012. She joined Universiti Teknikal Malaysia Melaka (UTeM) in December 2001 as a tutor and is currently a senior lecturer at Faculty of Electronic and Computer Engineering (FKEKK), UTeM. Her research interest includes process and device simulation of nanoscale MOSFETs device, advanced CMOS design, optimization approach (DOE) and process parameter variability. 